\title{
THE SYNTAX OF WATER, DARKNESS AND DEATH IN SYLVIA PLATH'S CROSSING THE WATER
}

Sigrid Renaux*

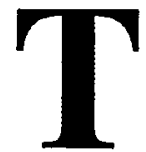

he title poem of the collection Crossing the water belongs to the third and final phase of Sylvia Plath's oeuvre, which was marked by an intense poetic development and creativity. As Ted Hughes comments, “'Crossing the Water', 'Among the Narcissi' and 'Pheasant"', all written within three or four days of one another in early April 1962, are unique in her work. And maybe it was this achievement, inwardly, this cool, light, very beautiful moment of mastery, that enabled her to take the next step."1

Although Plath has not taken part in the selection of poems in Crossing the water, for the collection was published posthumously in 1971, Hughes' choice of the title poem for this volume seems significant in its suggestion of movement, of transition through a material element, and thus of creative effort,

* Universidade Federal do Paraná.

1 STEVENSON, Anne. Bitter fame: A life of Sylvia Plath. London: Penguin Books, 1989 , p. 236. 
since there is no doubt about "Plath's technical, thematic, and imaginative coming of age" in these poems, as "she has learned a new vernacular, (...) now manifest in slant-rhyme couplets, variations on the staid tercet and quatrain, idiosyncratic rhythms, and cleverly cumulative image patterns". Inside this "coming of age", it is exactly the last quality which attracts us so much to her poetry - and here, specifically, to Crossing the water, with its strange combination of form, event and substance.

In my reading of the poem, I shall be making use of some of Gaston Bachelard's concepts on the imagination of matter, as found in Water and dreams - a work which, in his own words, "remains an essay in literary aesthetics. It has the dual objective of determining the substance of poetic images and the suitability of particular forms to fundamental matter" ${ }^{3}$ - since they provide us with an entrance not only to the superficial, but mainly to the more profound levels of Plath's clusters of imagery. As Bachelard further argues in the Introduction "Imagination and Matter",

The imagining powers of our mind develop around two very different axes.

Some get their impetus from novelty (...) the picturesque, the varied, and the unexpected. (...)

Others plumb the depths of being. They seek to find there both the primitive and the eternal. They prevail over season and history. (...) they produce seeds - seeds whose form is embedded in a substance, whose form is internal. ${ }^{4}$

Plath confirms and recontextualizes Bachelard's concepts, when she states, in a $\mathrm{BBC}$ interview, that

I think my poems immediately come out of the sensuous and emotional experiences I have, but I must say I cannot sympathize

2 BROE, Mary Lynn. Protean poetic: The poetry of Sylvia Plath. Columbia: University Missouri Press, 1980, p. 81.

3 BACHELARD, Gaston. Water and dreams: An essay on the imagination of matter. translation by E. R. farrel. Dallas: The Pegasus Foundation, 1994, p. 10.

4 lbid., p. 1. 
with these cries from the heart that are informed by nothing except a needle or a knife, or whatever it is. I believe that one should be able to control and manipulate experiences, even the most terrifying, like madness, being tortured, this sort of experience... with an informed and an intelligend mind... personal experience is very important, but certainly it shouldn't be a kind of shut-box and mirror-looking, narcissistic experience. I believe it should be relevant... to the larger things, the bigger things. ${ }^{5}$

This overlapping of arguments is the starting point for a productive interrelashionship which can be established between the poet and the philosopher-poet, as one can deepen and thus enrich the analysis of Plath's poems with Bachelard's insights into the imagination of matter. Thus, from his studies of clear waters with its reflective narcissism to his examination of deep, dormant and dead waters, the Charon complex, water in combination with other elements, among other concepts, one can establish parallels not only with "Crossing the Water", but with Plath's own strategy in writing poetry, which stems from a sensuous and emotional experience but necessarily passes through the depth of her being and thus becomes relevant "to the larger things, the bigger things". As will be seen, Plath works simultaneously with what Bachelard distinguishes as

two sorts of imagination: (...) a formal imagination and a matcrial imagination.(...) these concepts seem to me indispensable for a complete philosphical study of poetic creation. Causes arising from the feelings and the heart must become formal causes, if a work is to possess verbal variety, the everchanging life of light. Yet besides these images of form (...) there are (...) images that stem directly from matter. (...)

Of course, there are works in which the two imagining powers cooperate. It is not even possible to separate them completely. ${ }^{6}$

5 BROE, p. 104.

6 BACHELARD, p. 1. 
Graphically, the poem is a mixture of tradition and innovation, as it is composed of four triadic stanzas, with end-stopped lines of irregular lengths, and in which end-rhyme is substituted by other sound parallelisms:

Black lake, black boat, two black, cut-paper people.

Where do the black trees go that drink here?

Their shadows must cover Canada.

A little light is filtering from the water flowers.

Their leaves do not wish us to hurry:

They are round and flat and full of dark advice.

Cold worlds shake from the oar.

The spirit of blackness is in us, it is in the fishes.

A snag is lifting a valedictory, pale hand;

Stars open among the lilies.

Are you not blinded by such expressionless sirens?

This is the silence of astounded souls. ${ }^{7}$

Examining the poem first in its isolated images, I will simultaneously be concerned with the symbolism inherent in them, in order to deepen our understanding of a particular image. Since "significant indefiniteness is the mark of symbols" I will be dealing only with the associations which could be pertinent in the context of this poem, as they will lead to the formation of the dominating image/substance of the poem. As Bachelard again confirms,

if the reader can be convinced that there is, under the superficial imagery of water, a series of progressively deeper and more

7 PLATH, Sylvia. Collected poems. Introd. by Ted Hughes London: Faber \& Faber, 1981. p. 190.

8 VRIES, Ad de. Dictionary of symbols and imagery. Amsterdam: North-Holland Publ. Co., 1974. Preface. All symbols references will be taken from this edition. 
tenacious images, he will soon develop a feeling for this penetration in his own contemplations; beneath the imagination of forms, he will soon sense the opening up of an imagination of substances. He will recognize in water, in its substance, a type of intimacy that is very different from those suggested by the "depths" of fire or rock (...) that water is also a type of destiny (...) an essential destiny that endlessly changes the substance of the being. ${ }^{9}$

Thus, the imagery in the title immediately creates an expectancy, due, on the one hand, to the suggestiveness of the symbolism of water as chaos water, transition between the etherial and the solid, between life and death, dissolution, instability, knowledge and memory stored in the unconscious; on the other, to its associations with the ancient tradition of crossing the water, as a funereal journey over water, leading to what Bachelard calls "a culture complex".

Nevertheless, this expectancy needs to be contextualized and confirmed by what the poem wil reveal: not a real but an oneiric world, in which everything is pervaded by the symbolism of water, as everything is suspended above, floating on or submersed in water. Entering this world, we find, from the start, the recurrence of images of blackness totally impregnating the first stanza: not only "a black lake", a "black boat", "two black, cut-paper people", but also "black trees" and "shadows". The color black, symbolizing and suggesting prime matter, the darkness of the underworld, mourning, penitence, fermentation and putrefaction, mystery, night, death as complete annihilation, will thus contaminate not only the images it precedes, but also affect the other images on the "black lake", by retaining only their negative associations.

The image of the lake qualifies and reconfirms the symbolism of the material element "water" of the title, by its associations with the occult, the mysterious, prime matter, transition of life to death, the underwater realm from which the sun rises and into which it sinks, land of the dead, the unconscious for the lake is black, suggesting that its positive associations as resurrection, revelation, a mirror for self-contemplation, source of creative power, are gone in this context .

The blackness of the lake is then extended to the boat, retaining thus only its negative symbolism the boat of evening-death, the funerary boat which

\footnotetext{
9 BACHELARD, p. 5-6.
} 
accompanied the mummy to the grave, as well as Charon's boat, in which the souls of the dead are ferried across the Styx - all of them related again to the symbolism of water and pointing to the next image: the "two black, cut-paper people" in it. These two people are no longer real, but simply countours of black, cut-paper, not only insubstantial but also as transitory as paper, thus corroborating their state of transition, gliding slowly onwards on the black surface of the lake. The number two, symbolizing dualism (positive/negative, life/death), shadow, reflection, primordial matter, besides being the number sacred to Pluto, god of the Underworld, again corroborates the transitory and shadowy state of the passengers.

In this way, what would simply have been a poem coming out of Plath's "sensuous and emotional experiences", or her formal imagination, gradually becomes a poem whose images stem directly from the depths of her material imagination, for the recurrence and overlapping of associations in these images allow us to speak already of a strange combination of Bachelardian Form, Event (becoming) and Substance (matter): ${ }^{10}$ darkness, journey, and water, with their associations of an underworld atmosphere, of transitoriness - the crossing leading to death. For this reason, Bachelard's conceptualizations not only confirm this reading but add to it his philosophic profundity, as he discusses the Charon complex as a "culture complex" formed by natural dreams and learned traditions:

If we are willing to restore to their primitive level all the unconscious values that have been grouped around funeral rites by the image of a journey over water, we shall better understand the meaning of the river of Hades and all the legends concerning the funereal crossing. (...) Having passed through earth or fire, the soul arrives at the waters edge. Profound imagination - material imagination - wants water to have its part in death; water is needed for death to keep its meaning of a journey. (...) for such infinite dreams, all souls, whatever the nature of their funerals be, must board Charon's boat. (...) The persistence of a poetic and dramatic attraction to such an image, (...) can serve to show us that natural dreams and learned traditions come together in a culture complex (...) [the] Charon complex. ${ }^{11}$

10 BACHELARD., p. 65.

11 Ibid., p. 75-6. 
As he goes on saying, "under cover of the most diverse, the most unexpected images, this theme is guaranteed stability because it possesses the strongest of unifying forces: oneiric unity". ${ }^{12}$

If the first line already presents the theme of the poem in a microcosm, line two continues this strange syntax, by introducing another image of blackness - "Where do the black trees go that drink here?" - in which the black trees seem not only literally to take in water from the lake, through their roots, but also in the sense that their immense shadows absorb and are absorbed by the black surface of the lake. The image of the tree - with its associations of cosmic life as it connects the three worlds, as well as of vegetative life, immortality, human nature, prime matter - has its positive symbolism thus also contaminated and consequently negated by the qualifier black, which is then further reinforced by line three, "Their shadows must cover Canada". The rhetorical question, attributing movement to the trees, suggests perhaps that this movement comes from their reflections gliding with the boat like the two black shadows in it, as the associations this new image brings: symbolizing neither body, nor soul, as well as life, gloom, obscurity, death, ghost, departed spirit, reflection, image, the shadow again retrieves symbolism in common with the other images in this stanza, as well as adding a new texture and shape to blackness. In its turn, Canada, as a geographical location, reminds us of Plath and Hughe's driving and camping tour at Rock Lake, Ontario ${ }^{13}$ but, more than a real landscape, it seems to stand for the vastness of a northern region, thus reflecting back on the immensity of the shadows of the trees in the poem, which "must cover" a whole country. Even more, it will become part of the poem's dreamy waterscape, as "before becoming a conscious sight, every landscape is an oneiric experience". 14

Further, all these related images in the first stanza are interspersed with subtle sound parallelisms: after the fourfold and forceful repetition of "black", which foregrounds the sombre atmosphere of the scenery, alliteration "black boat" and "cover/Canada", assonance in "lake/paper", "black/shadow/Canada", "people/trees" and consonance in "where/here/their" may seem minor effects, but all of them contribute in bringing sound and meaning together. In this way, although the lines in the poem are end-stopped, the parallelisms in sound and meaning reverberate from one line and one image to the next, anulling formal

12 BACHELARD., p. 77.

13 STEVENSON, p. 159.

14 BACHELARD, p. 4. 
frontiers and thus foreshadowing the fluidity that will become foregrounded in the next stanzas.

Stanza II introduces only "a little light" into the overall darkness of the scene - with its associations of cosmic energy and spiritual life necessarily reduced through "little" - a light that seems to be there just to give shape to the water flowers. This is confirmed by act of filtering, the only three-syllable word in this stanza, which projects, by its length, the slow movement of a liquid light filtering through like water, from the flowers. The whole of stanza I thus has its blackness enhanced exactly through the little light dropping from these flowers, and coming not from above, but from below, further implying an underworld/underwater atmosphere. Again inside the general symbolism of water, these flowers have the beauty of their color and shape associated to their transitoriness - thus evoking the images in line one - besides also symbolizing death and regeneration, the mystic centre, star on earth and archetype of the soul.

The leaves, in direct contact with the water, iconize by their round and flat shape the surface of the lake, and, like the black lake, they are also full of darkness, in contrast to the "little light" emanating from the flowers. But "full of dark advice" has further connotations, as "dark" also means gloomy, sombre, evil, obscure, secret, and therefore it is as if water were transmitting, through the "voice" of the leaves (associated with people, divination, death, and compared to ghosts), sombre "advice" (from advisum: ad to + visum, pp. of videre, see), or foreseeing, thus creating simultaneously an atmosphere of foreboding - as if the ghosts of the dead in the black waters were warning the two shadows not to hurry in their crossing of the lake.

In contrast to the heaviness of the plosives in line one, foregrounding the physicality of the images, the sound parallelisms in line four $-1 / 1 / 1 / r / r / r / 1 / r$ (plus the alliteration "little light" carrying on as a chiasmus into "filtering" and then "flowers") - and then continued in lines five $-r / 1 / r-$ and six $-r / 1 / 1 / r-$, contribute to enhance the liquid quality not only of the flowers and leaves but of the whole stanza, as the content demands. As in stanza I, most other sound effects are unobtrusive, as the alliteration "flat/full" joining the two qualities of the leaves, together with the chiasmus formed by "round/dark", while the assonance "light/ advice" opens and closes stanza II - the light seen filtering from the flowers becoming the dark foreseeing of the leaves. But even more separate sound parallelisms, such as assonance in "people/trees/leaves", and alliteration in "here/hurry", "drink/dark" contribute to the overall toned down sonorous atmosphere, in keeping with the darkness of this poem, and neutralizing again the impact of the end-stopped lines. 
The roundness of the leaves in stanza II seems to become transposed into stanza III, in the image of the "cold worlds", for the world, besides denoting time, state, or scene of existence, the universe, all creation, the earth, also suggests immensity, the macrocosmos reflected in its smallest units as microcosmos, thus retrieving the concentric circles on the water surface formed by the oars, in continuous expansion; and, by also symbolising transitoriness, the finite, the "cold worlds" also retake the symbolism of the transitoriness of water, corroborating their being created by the movement of the oars. The qualifier cold, besides transmitting its quality of low temperature "to worlds", not only adds to them connotations of being unmoved, without ardour, friendliness, or affection, but also of death, by the worlds being inside the black lake. Oars, in its turn, again connotes material progress through water as matter, creative thought, in the sense that these dead cold worlds are again shaken, disturbed, and thus awakened through the touch of the oars. Thus shake becomes the strongest word in the poem, for it actually brings both worlds - of the living and of the dead, of the upper and of the underworld - together, through the oar. This transposition is further confirmed at the level of sound, for "cold worlds", besides forming an imperfect rhyme and an eye rhyme - also shares parallelisms of sound with oar, as if "worlds" partially contained "oar" and even "cold".

The colour black is retrieved in line eight, - "The spirit of blackness is in us, it is in the fishes" - the longest in the poem, in which the identification water/boat/people with blackness achieves its climax: here blackness, from being a material substance, Prime Matter, becomes a concept, a spirit, an incorporeal existence which pervades not only "us" - the two people who have become individuated in "us" - but also the inhabitants of the underwater world, the fishes. In consequence, the fishes, with their positive associations of life, fertility, abundance, resurrection, immortality, negated through the "spirit of blackness", become symbolic of the end, the souls remaining in the darkness of the primordial waters. In this way, the paralellism of form and meaning in "the spirit of blackness is in us/it is in the fishes", with "us" even echoing the last syllable of "fishes" and thus being contained in it, corroborates that both people and fish are in contact above and below the water through the boat and the oar, and further foregrounds the expansion of the words "black" and "dark" from the first two stanzas into line eight, completing this first part of the poem. What comes next, is almost complementary.

The snag - this pointed root or stump embedded in the lake, and thus in contact with the underworld, but pointing out of the water - has its associations of fertility (as the bough) inverted, on the one hand, because it is iconized as a pale hand, "pale" symbolizing coldness, the unconscious, death; on the other, 
it has its symbolism enriched by this visual similarity to the "hand" - suggesting, by its paleness, not strength, authority, protection, greeting, a blessing, but only death's white hand, a sign of farewell from the dead, a warning, and thus a "dark advice", while lifting reinforces the idea that this hand comes from the underwater realm, like the hand of a drowned person. This sign of warning or farewell is further confirmed through the qualifier valedictory, simultaneously the longest and most learned word in the poem - with its original meaning of vale (from the Latin imperative of valere $=$ be well, be strong) + dicere (to say) $=$ words of farewell - thus pointing to its significance. But its original meaning is anulled, for the pale hand that bids farewell has lost is strength, rising as it does from the cold and dead worlds of the lake, and the only message it sends is wordless. Simultaneously, although this line formally parallels line four, in contrast to the continuous action connoted by the present participle in "a little light is filtering", here the present participle adquires an ominous immediacy, as if the pale hand is in the act of rising from the water, its paleness retrieving, again in an ominous way, the "little light" from the flowers, the hand almost becoming the skeletal image of a flower, thus drawing the two stanzas even more together and further highlighting the "spirit of blackness" that pervades the scene.

The last stanza, which starts with the image of stars opening among the lilies, again makes the material and symbolic worlds above and below the lake surface overlap, like mirror images: the stars, by their shape and light, iconize the floating water-lilies with their broad leaves and white flowers - thus retrieving the symbolism of the flower as star - and also the light filtering from them; and, by their symbolism - as heavenly light, immortality, hope, animated spirits, the soul - the stars also recover the symbolism of the water-lilies or nymphaeas - as immortality, grief, remembrance, tipifying the purified soul at funerals. In this way, the spirit of blackness - as substance and as concept although pervading the poem, does not hinder stars from opening among the water flowers, or beauty to appear in nature, and thus symbolic of hope blossoming in the soul - the souls in the darkness of primordial waters, as all souls must board Charon's boat.

The water lilies also provide a transition to the image of the sirens in the next line, for their Latin word "nymphaeas" formalizes the appearance of the word sirens - these water nymphs/nymphaeas - who by their seductive singing fascinated those who sailed by their island and then destroyed them. By being connected with the fish-woman (mermaid) and with the element water, the sirens also symbolize unseen sea-dangers, the death-bearer, or death-wish, in this way intensifying once more the reflection of one water image in the other, in ever 
larger circles, as the correspondence of the symbolisms of the water flowers as lilies, stars and sirens confirms.

But the nymphs/nymphaeas are expressionless - both in their aspect and intonation of voice, as, literally, in the sense of being deprived of words - for, as death-bearers, these sirens/nymphs do not sing, which is further highlighted by the word "sirens" being actually contained in "expressionless", thus increasing the tightness of their semantic relationship. In this way, the pale hand that gives a "speechless" valedictory message is followed by another "expressionless" song, seeming to confirm that these unuttered voices come from the dead. The absence of sound in these expressionless sirens/nymphs/lilies/stars - whose only expression is their filtering a "little light" - explains the paradoxical use of blinded, in the sense that in,that overwhelming blackness, whatever little light shines, as from these star-flowers, would dazzle the eyes by its brilliance, and, further, would also deprive one of the power of insight, as "astounded souls" will confirm.

Simultaneously, this expressionlessness becomes reflected, in the next line, in "the silence of astounded souls", not only in terms of meaning, but literally, as "silence", is contained in "expressionless" and, in an almost perfect identification of sounds, reechoes "sirens", as if the sirens had become silent charming us not by their song, but by their silence - this essential quality in many charms. The abstractedness of the concept of souls, already part of the symbolic reverberations of many images above and symbolic itself of the immortal part of man, his creative part, the light and fire within him, has its symbolism and meaning further qualified by astounded, suggesting not only astonished, amazed, but also shocked with alarm or surprise. In this way, in a parallelism of meaning, it retrieves not only the images of the cold worlds "shaken" from the oar, but mainly the image of the two black, cut-paper people, "blinded"/dazzled by the light in the lilies - these wordless sirens - and thus also two "astounded souls" in transition to another realm.

Parallelisms in sound again reinforce these concentric images, in the alliteration, initial rhyme and end rhyme which intermingle in "sirens/silence/souls", alliteration in "stars/astounded" and partial alliteration in "astounded/souls", plus the sonority of the diphthongs in blinded/sirens/silence and astounded/souls. The prominence of liquids and nasals contributes to make the last stanza the most sonorous and fluid in the poem, in contrast with the plosives and almost stacatto rhythm of the first stanza, confirming the gradual transition from one state to another, from the dark substantiality of the boat and the two cut-paper people to the fluidity and immateriality of the astounded souls, in their funeral crossing, from the immortality of the stars, plunged into the water lilies, 
to the deadness of the pale hand, protuding from the water - this horizontal surface which is simultaneously the meeting point of the three worlds, as underneath one senses the "deeper and more tenacious images" of water as a "type of intimacy", in Bachelard's words above, as "an essential destiny that endlessly changes the substance of the being".

In this way, what has started as a real experience becomes, in the poem, much more than an exercise of ordinary reverie, of Plath's formal imagination, in her presentation of an almost impressionistic glimpse into a black waterscape, faintly illuminated by flowers/stars, in which we detect the black shadows of two people in a boat. As we progressively penetrate into the text, the strong symbolic and cultural connotations of "crossing the water", leading us into a literary reverie - the Charon complex -, are further confirmed through the oneiric unity of all the images which not only reflect on the surface of the poem, but also emerge from its depths. The meandering of these images/symbols, like their sinuous sound parallelisms, thus create a strange but melodious syntax of water, darkness and death, in which even the subtle glimpses of light are overshadowed by the all encompassing "spirit of blackness" which involves this last ossing the water. Even more: as we move from description to thought, we realize how this syntax becomes, in Plath's material imagination, one single symbolic force, as water, darkness and death interpenetrate and absorb one another, in the poet's attempt to present the imagination of death ${ }^{15}$ by rwemaining faithful to her oneiric realities.

\section{RESUMO}

O artigo faz uma leitura bachelardiana do poema "Crossing the Water", de Sylvia Plath, a fim de determinar a função que a água, como elemento da imaginação material e portanto como imagem poética, exerce no contexto deste poema. temporânea.

Palavras-chave: Sylvia Plath, Gaston Bachelard, poesia norte-americana con-

BACHELARD, p. 81. 


\begin{abstract}
This article analyses Sylvia Plath's poem "Crossing the Water", by way of Bachelard's Water and dreams, in order to determine the function that water, as an element of material imagination and thus as a poetic image, exerts in the context of this poem.
\end{abstract}

\title{
REFERÊNCIAS BIBLIOGRÁFICAS
}

BACHELARD, Gaston. Water and dreams: An essay on the imagination of matter. Dallas: the Pegasus Foundation, 1994.

BROE, Mary Lynn. Protean poetic: The poetry of Sylvia Plath. Columbia: University of Missouri Press, 1980.

PLATH, Sylvia. Collected poems. With an Introduction by Ted Hughes. London: Faber \& Faber, 1981.

STEVENSON, Anne. Bitter fame: A life of Sylvia Plath. London, Penguin Books, 1989. VRIES, Ad de. Dictionary of symbols and imagery. Amsterdam: North-Holland Publ. Co., 1974. 